\title{
THE MORPHO-SYNTACTIC AND SEMANTIC-PRAGMATIC REALISATION OF DEFINITENESS AND SPECIFICITY IN SWAHILI
}

\author{
Gerald Eliniongoze Kimambo
}

\begin{abstract}
This paper studies the realisation of definiteness and specificity in Swahili. Available literature on the realisation of definiteness and specificity in Swahili focuses mainly on the morphological domain and only marginally on the syntactic domain. Nevertheless, definiteness and specificity lie at the interface between morpho-syntactic and semantic-pragmatic domains. Grounded in Lyons' (1999) semantic model, this paper descriptively shows how definiteness is realised in Swahili by considering the notions of 'familiarity,' 'identifiability,' and 'uniqueness (as well as inclusiveness).' In addition, it shows how specific and non-specific entities are realised in the language. The paper thus offers a more holistic perspective on the realisation of definiteness and specificity in Swahili.
\end{abstract}

Keywords: Morpho-syntactic, Semantic-pragmatic, Definiteness, Specificity

\section{Introduction}

\subsection{Definiteness and specificity in Bantu}

This section explores the realisation of (in)definiteness and (non-)specificity in Bantu to enable the reader to understand how the realisation of (in)definiteness and (non-)specificity in Swahili concurs with or differs from that of other Bantu languages. The realisation of these notions in Bantu generally involves the interplay of morphological, syntactic, semantic and pragmatic processes. Literature on Bantu reveals that definiteness and specificity are realised mainly through pre-prefixes, subject markers, object markers, demonstratives and the context of interaction (Alnet 2009; Mojapelo 2013; Petzell 2003; Progovac 1993; Riedel 2009; Visser 2008). This section explores what each of these elements realise in selected Bantu languages.

To begin with, pre-prefixes are word-initial elements that precede noun class markers in the nominal domains of most Bantu languages (Petzell, 2003). The use of pre-prefixes is somewhat complex. Pre-prefixes do not seem to fulfil one common function across all Bantu languages, rather they interact with other elements to realise 
Kimambo: The morpho-syntactic and semantic-pragmatic realisation of definiteness and specificity in Swahili

definiteness and/or specificity. For instance, in Kinande [D42] (Maho) ${ }^{1}$, the presence or absence of pre-prefixes distinguishes specific from non-specific readings but does not distinguish definite from indefinite readings. Likewise, Gambarage (2013), Petzell (2003) and Visser (2008) report that pre-prefixes realise specificity in Nata [E45], Kerewe [E24] and isiXhosa [S41] respectively. However, in Kagulu [G12], Petzell (2003) shows that pre-prefixes interact with syntax and semantics as well as with the context of interaction to realise definiteness, specificity and topicality, as in the following examples.

(1) Nikutandika masasi ga wana.

ni- ku- tandika masasiga wana

SM.1SG PRES ${ }^{2}$ spread 6-bed of 2-child

'I make the children's beds.'

(2) Awana wang'hakonga kulila...

a- wana wa- ng'ha- konga kulila

PrPr2- child SM2 COND start 15-cry

'If the children start to cry...' (Petzell, 2003:7)

According to Petzell, in (1), wana 'the children' are introduced in the discourse context. In (2), awana 'the children' are mentioned for the second time. Petzell says that the pre-prefix $\boldsymbol{a}$ shows topicality, and awana 'the children' "anaphorically" refers to wana 'the children,' who were previously mentioned in (1). In my view, the anaphoric reference depicted in (2) leads to definiteness via familiarity (cf. Lyons, 1999). Considering Lyons' semantic framework, therefore, not only does the pre-prefix in (2) denote topic in Kagulu (according to Petzell) but also definiteness. Regarding specificity, Petzell reports that a pre-prefix is used when the noun in question is specified. According to Petzell (2003), definiteness and specificity are realised by preprefixes in Kagulu because such elements are used for things that are familiar to both the speaker and the hearer or for things that are specific in the context of interaction. A similar observation was made by Hyman and Katamba (1993) for Luganda. According to these scholars, pre-prefixes in Luganda are associated with definiteness, specificity and focus.

Subject marking and the subject position can also denote definiteness. In Northern Sotho [S31c], for instance, Mojapelo (2013) reports that the subject marker

\footnotetext{
${ }^{1}$ In referring to these Bantu languages, I use Maho's (2009) updated list of Guthrie's (1967) classification of Bantu languages.

${ }^{2}$ In this paper, $\mathrm{COND}=$ condition, $\mathrm{fv}=$ final vowel, $\mathrm{OM}=$ object marker, $\mathrm{PrPr}=$ pre-prefix, prf $=$ perfect, prs $=$ present, pst $=$ past, $\mathrm{SG}=$ singular, and $\mathrm{SM}=$ subject marker.
} 
(SM) is related to definiteness. According to her, this element is never used for indefinite entities in the language. In addition, indefinite nouns are not allowed in the subject position in Northern Sotho. In Mojapelo's data, when a simple definite subject was moved to the initial position of a clause, it co-occurred with a definite determiner.

Object markers also denote definite and/or specific entities in Bantu. To begin with isiXhosa [S41], Visser (2008) demonstrates that the presence and absence of an Object Agreement (OA) marker denotes specificity and non-specificity respectively. This means (in)definiteness distinctions are not arrived at via object marking in isiXhosa.

As regards Sambaa [G23], Riedel (2009) reports that, when the object in question is a proper name in a simple clause, it must be object marked, as shown in (3) below.

a. Nzamwona Stella.

$$
\begin{array}{lllll}
\text { N- } & \text { za- } & \boldsymbol{m} \boldsymbol{w}- & \text { ona } & \text { Stella } \\
\text { SM1 } & \text { Perf } & \boldsymbol{O M} & \text { see } & \text { Stella }
\end{array}
$$

'I saw Stella.'

$$
\text { b. *Nzaona Stella (Riedel, 2009:44) }
$$

Likewise, kinship terms such as father and unique titles when used as proper names must be object marked in Sambaa. Moreover, Riedel notes that terms referring to those with high status (such as askofu 'bishop') are often object marked in Sambaa. Otherwise, the construction becomes ungrammatical, as illustrated in (4).

(4)
a. Nzamwona tate.
N- za- $\boldsymbol{m} \boldsymbol{w}$ - ona tate
SM1 Perf $\boldsymbol{O M}$ see father
'I saw father.' [Kinship term]
b. Nzamwona askofu.
$\mathrm{N}-\quad$ za- $\boldsymbol{m} \boldsymbol{w}$ - ona askofu
SM1 Perf $\boldsymbol{O M}$ see bishop
'I saw the bishop.'
c. $\quad * N z a o n a$ askofu

(Riedel, 2009:45)

In my opinion, objects such as those in (3) and (4) receive OMs in Sambaa because they are unique in their respective contexts. In (4a), for instance, 'Stella' is a uniquely identifiable person in the context of interaction (cf. Givón 1978; Lyons 1999). 
Kimambo: The morpho-syntactic and semantic-pragmatic realisation of definiteness and specificity in Swahili

In line with Visser (2008), proper nouns and pronouns are generally considered definite since both the speaker and the hearer assume their identifiability. Similarly, studies on object marking in Chichewa (Bresnan \& Mchombo 1987), isiZulu (Zeller 2012), Nata (Gambarage 2013), Nyaturu [F32] (Hualde 1989), Kiluguru [G35] (Marten \& Ramadhani 2001), Kirimi (Hualde 1989), Kivunjo [E62b] (Bresnan \& Moshi 1990) and Shona (Mugari 2013) indicate that object marking interacts with definiteness in these languages.

Concerning Swahili, Riedel (2009) says that object marked and non-object marked entities can be (in)definite or (non-)specific. Riedel (2009:51) claims further that, in Tanzanian Standard Swahili, specificity always requires object marking. According to Riedel, if an object is specific, it is obligatorily object marked. If it is nonspecific, it is not object marked. Such a conclusion was also reached by Cann, Kempson and Marten (2005) and Woolford (1999). However, to Hinnebusch and Kirsner (1980), Kimambo (2018), and Seidl and Dimitriadis (1997), object marking in Swahili is associated with definiteness. What is more, midway between this diversity of viewpoints, Keach (1995) holds that object marking realises both definiteness and specificity for inanimate objects in Swahili.

Demonstratives are also used for definite referents in Bantu. They have in common the property of pointing to a particular referent. Their canonical positions within NPs differ from one language to another. Whereas in some languages they occur pre-nominally, in other languages they occur post-nominally or both pre-nominally and post-nominally (Dryer 2005). The difference between pre-nominal and post-nominal demonstratives is that, whereas the former function akin to the English definite article, the latter function as demonstratives-proper (Dryer 2005; Van de Velde 2005). Studies such as Alnet (2009), Gambarage (2013), Iribemwangi and Kihara (2011), Nurse and Philippson (1977) and Iorio (2011), respectively, report that demonstratives are used for definite referents in Maore [G40], Nata [E45], Gĩkũyũ [E51], Kimochi [E62a], and Bembe [D54].

In summary, these languages realise definiteness and specificity via the interplay of linguistic and extra-linguistic mechanisms. Linguistically, pre-prefixes, subject markers, object markers and demonstratives play key roles in (in)definiteness and/or (non-)specificity distinctions in Bantu. When these elements are used in a clause, the noun becomes definite and/or specific. Yet, these elements do not fulfil similar roles in all of the Bantu languages; for instance, while pre-prefixes realise specificity in isiXhosa, such elements interact with definiteness in Luganda. Moreover, while OMs realise specificity in isiXhosa and in Nairobi Swahili, such morphemes interact with definiteness in isiZulu and in Sambaa. Extra-linguistically, the context of interaction plays a significant role in (in)definiteness and (non-)specificity distinctions in Bantu. 
Literature on definiteness and specificity in Swahili focused mainly on their morphological realisations (Seidl \& Dimitriadis 1997; Riedel 2009), and less attention was paid to syntactic realisations (Vitale 1981). However, as mentioned previously, the realisation of definiteness and specificity lies at the interface between morpho-syntactic and semantic-pragmatic domains (Zamparelli 2005). Employing Lyons' (1999) semantic framework, this paper describes the realisation of definiteness and specificity in Swahili to enable the reader to understand how, on one hand, Familiarity, Identifiability, Uniqueness (and Inclusiveness) are used to indicate definiteness in Swahili, and on the other hand, how specific and non-specific entities are realised in the language.

\section{Theoretical framework}

This paper employs Lyons' (1999) semantic framework to study the realisation of (in)definiteness in Swahili. Lyons (1999) defined (in)definiteness in terms of familiarity, identifiability, and uniqueness (and inclusiveness). The following definitions show how (in)definiteness is understood in this study.

Regarding familiarity, a referent is definite if both the speaker and the hearer are familiar with it, while a referent is indefinite if only the speaker is familiar with it (Lyons 1999:3). Concerning identifiability, a noun phrase is definite if the hearer can identify it in the context of interaction (although it does not necessarily need to be familiar to him/her), while a noun phrase is indefinite if the hearer cannot identify it in the context of interaction (Lyons 1999:5ff).

Considering uniqueness (and inclusiveness), an entity receives the interpretation of definiteness when the hearer can associate it with a given description, because it is the only one that exists. Uniqueness is not absolute, but is pragmatically understood (Lyons 1999:7). For instance, before the marathon starts, one says 'the journalists are eagerly waiting to talk to the winner.' In this case, the winner is neither familiar nor identifiable but is pragmatically understood since there will be only one 'unique' winner (cf. Abbott 2006:126). If they are many, the winners would be definite via inclusiveness.

As for specificity, a noun phrase is specific if the speaker has a particular referent in mind, and it is non-specific if the speaker has no particular referent in mind.

\section{Data presentation and discussion}

\subsection{Definiteness in Swahili}

Lyons distinguishes between grammatical definiteness and semantic/pragmatic definiteness. Grammatical definiteness is realised via special overt morphological markers of definiteness such as articles in English and French, whereas semantic/pragmatic definiteness is realised via the context of interaction, as in Swahili 
Kimambo: The morpho-syntactic and semantic-pragmatic realisation of definiteness and specificity in Swahili

and Northern Sotho; these languages do not have articles. In the light of Lyons' (1999) semantic framework, the following subsections show how definiteness is arrived at in Swahili in terms of familiarity, identifiability, uniqueness and inclusiveness.

\subsubsection{Familiarity}

Recall that a referent is definite if both the speaker and the hearer are familiar with it (Irmer 2011; Lyons 1999). Familiarity is established in Swahili via linguistic and/or extra-linguistic means. Linguistically, this happens through anaphoric reference, and extra-linguistically, it happens through associative inference and encyclopaedic knowledge; these are demonstrated below:

i) Anaphoric reference

Anaphoric reference involves co-referring to a particular referent in the discourse by using linguistic elements (Fishman 1978; Mojapelo 2013). Since Swahili does not have articles, it uses demonstratives, pronouns, full NPs, SMs and OMs to fulfil this purpose. To begin with, three types of demonstratives are used in Swahili to refer to a particular referent that has already been mentioned in the preceding discourse: $h$ - (for a proximal referent), $h-o$ (for a medial referent) and -le (for a distal referent). The following Swahili example translated from Lyons (1999:3) is illustrative ${ }^{3}$.

$$
\begin{aligned}
& \text { Mwanamke mrembo na mwenye nywele nyeusi, mwanamume } \\
& \text { mtanashati mwenye miwani myeusi waliingia ndani. Muda si mrefu } \\
& \text { nikamtambua mwanamke yule. Wale watoto ni kama nilishawahi } \\
& \text { kuwaona pia. } \\
& \text { 'An elegant, dark-haired woman, a well-dressed man with dark } \\
& \text { glasses, and two children entered the compartment. I immediately } \\
& \text { recognized the woman. The children also looked vaguely } \\
& \text { familiar.' (Lyons 1999:3). }
\end{aligned}
$$

In the example above, two important observations can be made. First, Swahili uses post-nominal demonstratives such as yule 'that' for anaphoric reference, as in mwanamke yule 'the woman.' Second, it uses deictic demonstratives such as wale 'those' to denote topicality, as in wale watoto 'the children.' Ashton (1944), Dryer (2005), Lyons (1999) and Perrot (1951) argue that deictic demonstratives in Swahili

\footnotetext{
${ }^{3}$ Four Swahili native-speaking translators who were teaching at the University of Dar es Salaam during the time of data analysis verified the data presented in this paper.
} 
are similar to the in English, and they usually occur in the subject position. Their argument concurs with Mojapelo (2013) and Zeller's (2008) observation that the subject position is the locus of topicality in Bantu. The subject position thus favours definiteness in Swahili. The anaphoric and deictic uses of the demonstratives depicted in the Swahili example above co-refer to mwanamke 'the woman' and watoto 'the children' who are familiar to the hearer by virtue of being previously mentioned in the preceding discourse. Semantically, therefore, both pre-nominal and post-nominal demonstratives denote definiteness in Swahili.

Another element used for making anaphoric reference is the Subject Marker (SM). In Swahili, the SM co-refers to a uniquely definite referent in the discourse. It is used when the subject being referred to is familiar to the hearer. Consider the following example.

(6) Paulo $\boldsymbol{a}_{i}$ lisafiri. A Aliporudi nyumbani, a $\boldsymbol{a}_{i}$ limkuta $\boldsymbol{m k e}_{j}$ wake $\boldsymbol{a}_{j}$ mejifungua mtoto. $^{4}$

'Paul travelled. When he returned home, he found his wife had borne a child.'

In this example, the subject markers $a_{i}$ ' 'he' and $a_{j}$ ' 'she' refer to the full nouns 'Paul' and 'his wife' respectively since these nouns have been previously mentioned in the discourse. This anaphoric function of the Swahili SMs in (6) is identical to the function of pronouns in English. If familiarity has already been established, the SM can be used for the subject, as in the second sentence in (6). Besides using SMs, Swahili of course also uses proper nouns such as Paul to refer to a person who is unique in the discourse context. In such a situation, the proper noun is immediately followed by the SM as in Paulo alisafiri 'Paul travelled' in (6).

Personal pronouns are also used for anaphoric functions in Swahili. They denote grammatical person (Lyons 1999). They always refer to uniquely definite entities in the discourse. For instance,

(7) Rozi alifurahia mpira. Yeye ni mwanamichezo.

'Rose loved the ball. She is a sportswoman.'

In (7), the use of the personal pronoun yeye 'she' points to the unique individual, Rozi 'Rose.' The personal pronoun does not point to any other person. Besides performing this function, pronouns such as sisi 'we,' nyinyi 'you/plural' and wao 'they' can occur before nouns to function as deictic demonstratives, as in the following examples.

\footnotetext{
${ }^{4}$ In this example, I use the subscripts $i$ and $j$ to indicate the SMs' anaphoric references to the antecedents Paulo 'Paulo' and $m k e$ '(his) wife' respectively.
} 
Kimambo: The morpho-syntactic and semantic-pragmatic realisation of definiteness and specificity in Swahili

(8) a. Sisi walimu tutajitahidi kwa kadiri ya uwezo wetu.

'We teachers will try the best we can.'

b. Nyinyi wanafunzi msome kwa bidii.

'You learners should study hard.'

c. Wao Watanzania watasherehekea mwakani.

'They/them Tanzanians will celebrate next year.'

In (8), sisi 'we,' nyinyi 'you (plural)' and wao 'they/them' point to the teachers, learners and Tanzanians respectively. Such functions are similar to that of deictic demonstratives in Swahili. Besides functioning as independent pronouns, personal pronouns in Swahili can denote topicality like deictic demonstratives do, as in (8). This argument strongly supports the widely accepted notion that personal pronouns point to particular definite referents.

\section{ii) Associative inference}

Definiteness in Swahili can also be realised through associating a given object with something that has been mentioned in the discourse. In this situation, Lyons (1999) says that anaphoric reference in combination with general knowledge enables the hearer to understand the object being referred to. The following Swahili examples translated from Lyons (1999) show this situation.

(9) a. Ilinibidi nikodi teksii kutoka kituoni. Tukiwa njiani, dereva aliniambia kulikuwa na mgomo wa mabasi.

'I had to get a taxi from the station. On the way, the driver told me there was a bus strike.'

b. Wamewasili sasa hivi kutoka New York. Ndege ilichelewa masaa matano.

'They have just got in from New York. The plane was five hours late.'

(Lyons 1999:3)

In (9a), dereva 'the driver' is definite because the hearer can associate it with teksii 'taxi.' In this context, the speaker assumes that the hearer is aware that normally a taxi has a driver. Likewise, in (9b), ndege 'the plane' is definite since the hearer can associate it with -wasili kutoka New York 'got in from New York.' Akin to (9a), the 
speaker assumes that the hearer is aware that a long distance journey - say from New York to Johannesburg - involves a plane. Pragmatically, therefore, both dereva 'the driver' and ndege 'the plane' in (9a) and (9b) above are definite. Note that there are no morphemes marking definiteness in the Swahili examples above. The hearer relies on both the previous mentions of the associated entities and the general knowledge of the contexts to construe what is being referred to in the discourse. The contexts of interaction provide the definite readings of the nouns above.

\section{iii) Encyclopaedic knowledge}

Encyclopaedic knowledge (as used in this paper) involves situational and the general knowledge types. The following examples show that definiteness is understood in relation to knowledge of the immediate situation.

(10) a. Tafadhali fungua dirisha, nahitaji hewa safi. 'Please open the window. I need fresh air.'

b. Weka haya mataulo masafi bafuni tafadhali. 'Put these clean towels in the bathroom please.'

c. Nasikia waziri mku amefanya tena mambo ya hovyo leo. 'I hear the prime minister behaved outrageously again today.'

(Lyons 1999:3)

All the examples in (10a-c) show that definiteness can be realised through shared knowledge of the immediate situation in which the interlocutors are. In (10a), dirisha 'the window' is in the immediate environment that the speaker and the hearer can both see. Bafu 'the bathroom' in (10b) is definite due to the assumption that normally a house has a bathroom. In this situation, the visibility of bafu 'the bathroom' is not germane to the understanding of what is being talked about since the situation is still immediate. In (10c), waziri mkuu 'the prime minister' is definite because it is assumed that the hearer knows that the person being talked about is the leader of their country. It should also be noted that previous mention is not mandatory for the hearer to understand the definiteness readings of such entities. Instead, he/she relies on his/her knowledge of the situation to understand what is being talked about. As for general knowledge, Examples 10d and 10e are illustrative.

d. Simba ni mnyama hatari.

'The lion is a dangerous animal.' 
Kimambo: The morpho-syntactic and semantic-pragmatic realisation of definiteness and specificity in Swahili

\section{e. Dunia ni duara. \\ 'The earth is round.'}

These examples show that whereas Swahili uses bare nouns in the encyclopaedic context, English uses the article "the" in the same context to denote general knowledge. Accordingly, Simba 'the lion' and Dunia 'the earth' in (10d) and (10e) above are generic referents.

\subsubsection{Identifiability}

The speaker can use a particular form of expression to direct the hearer towards a definite object. It is not necessary that the hearer should be familiar with the entity being described. The object should simply be identifiable in the context of interaction. For instance, in the classroom context where the teacher is writing on the board and wants to clean a section from it, without turning around, he/she asks Paul - a student who has just entered - Nipe dasta 'Pass me the duster.' Paul looks around and finds dasta 'the duster' (cf. Lyons 1999). In this setting, Paul did not know that there was a duster during the time of the teacher's utterance, but with the help of the words nipe dasta 'pass me the duster' and of the classroom context (encyclopaedic knowledge), he could identify it in their immediate context. The teacher assumed that Paul could identify dasta 'the duster' in the classroom context by matching it with his mental image of dasta 'the duster.'

\subsubsection{Uniqueness and inclusiveness}

Lyons (1999) noted that definiteness does not necessarily consider identifiability. Sometimes an object is definite but the hearer cannot identify it if asked to do so. In this case, we need to consider uniqueness (see also Abbot 2006). Uniquely definite entities can be realised in Swahili through linguistic elements and extralinguistic information.

Linguistically, Swahili can use Relative Markers (RMs) - especially when they modify head nouns. I illustrate this in the following examples.

(11) a. Paulo alivaa jaketi ambalo alilinunua muda huohuo. 'Paul wore the jacket that he just bought.'

b. Gari nitakalolinunua litakuwa la familia nzima.

'The car that I will buy will be for the whole family.' 
In (11a), the relative clause ambalo alilinunua muda hиohиo 'that he just bought' offers the context for the definite interpretation. The relative clause helps the hearer to exclude any other jacket that Paul has. Accordingly, jaketi 'the jacket' is unique in the discourse context; it is the only one Paul had just bought. Likewise, in the second example, nitakalolinunua 'that I will buy' is a post-modifying relative clause that specifies only the car that will be bought by the speaker (cf. Radden \& Dirven 2007). Likewise, the car is unique in this discourse context.

The -o- of reference in (11a) and (11b) uniquely refers to jaketi 'the jacket' and gari 'the car,' respectively, by virtue of being previously mentioned and modified by the relative clauses. The Swahili -o- of reference is also referred to as kihusiano (Loogman 1965:105) or o-form PRO (Barrett-Keach 1985:46). Semantically, this referential element denotes definiteness in Swahili (cf. Haddon 1955; Perrot 1969; Polomé 1967). In addition, Lipps (2011) says that the -o- of reference indicates the topic in Swahili. Recall that the Bantu description provided in Section 1 indicates that the topic position favours definiteness (see also the next section for additional data from Swahili).

Extra-linguistically, native Swahili speakers can utilise available contextual information (via encyclopaedic knowledge) to refer to a unique entity in the context of interaction, as in the following example.

(12) Nilikuwa harusini muda sio mrefu. Bibi-harusi alivaa nguo zenye rangi ya bluu.

'I've just been to a wedding. The bride wore blue.'

(Lyons 1999:7 emphasis added)

In this example, the speaker has used bibi-harusi 'the bride' in the initial position of the second sentence because he/she assumes that the hearer understands that normally a wedding has a bride. Thus bibi-harusi 'the bride' is definite not because the bride is familiar or identifiable to the hearer, but because she is unique in the wedding context. This means although the hearer is not familiar with bibi harusi 'the bride' and would not be able to identify her if he/she comes across her a day later, bibi-harusi 'the bride' is uniquely definite in the wedding context. Lyons also notes that for plural and mass nouns, definiteness is realised via inclusiveness. The following examples are adopted from Lyons (1999:10) and translated for illustration.

(13) a. Tumetoka kumwangalia Yohana akishindana. Malkia aligawa zawadi. 'We have just been to see John race. The queen gave out the prizes.'

b. Tunatoa zawadi mbalimbali, na washindi watakaribishwa London.

'We are offering several prizes, and the winners will be invited to London.' 
Kimambo: The morpho-syntactic and semantic-pragmatic realisation of definiteness and specificity in Swahili

In (13) above, zawadi 'the prizes' and washindi 'the winners' are not unique in the descriptions given. The reference is to all the prizes and all the winners (Lyons 1999). Since the uniqueness criterion does not apply to plural and mass nouns, each group of objects (in bold text) is definite via inclusiveness. Note also that the definiteness readings of the Swahili objects above are not overtly marked by any morpheme. Their definite readings are understood based on the knowledge of their immediate contexts of interaction.

\subsubsection{Word order}

Word order can also be used to realise definiteness in Swahili. ${ }^{5}$ Syntactically, Swahili has an SVO canonical order. This order can be altered due to several reasons, one of which is to realise definiteness, as in the following examples.

(14) a. Wanakijiji wa-me-jeng-a shule.

$(\mathrm{SVO})$

Villagers they-prf-build- school

'The villagers have built a school.'

b. Shule, wa-me-i-jeng-a wanakijiji.

(OVS)

school they-prf-it-build villagers

'The villagers have built the school.'

Example (14a) shows the Swahili canonical SVO order, whereas (14b) shows the derived OVS order. Vitale (1981) says that topicalisation can trigger the movement of an object from its canonical final position (cf. 14a) to the derived initial position (cf. 14b). Note that topicalisation lies "at the interface between syntax, semantics and discourse-pragmatics" (Valenzuela \& McCormack 2013:103). In Example (14b), the topicalised shule 'the school' is associated with given information, definiteness and emphasis. This observation concurs with that of Allen (1983), Lowrens (1981) and Zerbian (2007) that the topic position favours definiteness. ${ }^{6}$

\subsubsection{Inherently definite noun phrases in Swahili}

\footnotetext{
${ }^{5}$ Word order is also reported to distinguish definite from indefinite entities in Polish (Ekiert 2007; Świątek 2014) and Turkish (Dikilitas \& Altay 2011). Whereas a referent in the clause final position is indefinite in these languages, the same referent in the clause initial position is definite.

${ }^{6}$ Duarte (2011:83) also reports that in Changana - a Bantu language spoken in Mozambique - when an object is moved to the beginning of a sentence, it receives the Changana definite particle ' $a$ ' and therefore becomes definite. Accordingly, Duarte remarks that the initial position realises definiteness in Changana.
} 
Drawing on Croft's (2003:130) proposed hierarchy that shows reference to person and definiteness in (15) below, personal pronouns and proper names are inherently definite (cf. Lyons 1999; Rezai \& Jabbari 2010; Riedel 2009 and Seidl \& Dimitriadis 1997) and are used in Swahili for definite entities, as instanced in (16).

(15) First/second person pronouns $>$ third person pronoun $>$ proper names $>$ human common noun $>$ non-human animate common noun $>$ inanimate common noun

(16) Petro alimuona Paulo.

Petro SM1-PST-OM1-see-FV Paul

'Peter saw Paul.'

The proper names in the example above are definite since they refer to unique individuals in the discourse context. By mentioning Peter and Paul, the speaker refers to only the two people satisfying the description given since the hearer is familiar with them. Swahili personal pronouns also perform this function.

In addition, Swahili uses demonstratives to realise definiteness. Swahili demonstratives can appear pre-nominally or post-nominally. Lyons (1999) notes that pre-nominal and post-nominal demonstratives in Swahili perform distinct pragmatic functions. Whereas post-nominal demonstratives distinguish distance and make anaphoric reference, pre-nominal (or deictic) demonstratives (such as $h$-, $h \_o$ and -le) show that the referent is the current topic. Pre-nominal demonstratives function akin to the definite article in English (Ashton 1944; Dryer 2005; Perrot 1951).

In summary, this section has looked at the realisation of definiteness in Swahili based on Lyons' criteria of familiarity, identifiability, uniqueness and inclusiveness. Regarding familiarity, definiteness can be established in anaphoric contexts by using demonstratives, SMs, personal pronouns and RMs. Concerning identifiability, the context of interaction can be used extra-linguistically to realise definiteness. Likewise, RMs, proper names and personal pronouns can be used for uniqueness and inclusiveness, in addition to the context of interaction. Furthermore, word order can be used to realise definiteness, in particular by moving the object noun to the beginning of the clause (topic position). In the following section, I describe the realisation of indefiniteness in Swahili.

\subsection{Indefiniteness in Swahili}

An indefinite object is neither familiar nor identifiable to the hearer. In addition, it is neither unique nor inclusive in the description given. It occurs in the first mention environment, especially when the speaker introduces it for the first time in the discourse. Such an entity can be either specific or non-specific. An NP is specific when the speaker 
Kimambo: The morpho-syntactic and semantic-pragmatic realisation of definiteness and specificity in Swahili

has a particular referent in mind, while it is non-specific when the speaker does not have a particular referent in mind (Lyons 1999). The following example shows how indefiniteness is indicated in Swahili.

(17) [First mention context]
a. Lucy ameokota kitu.
'Lucy has picked up something.'

b. Paul amenunua shati.

'Paul has bought a shirt.'

The first mention of kitu 'something' in (17a) and shati 'a shirt' in (17b) above realise indefiniteness. Note that there are no special markers of indefiniteness in Swahili. The language does not grammaticalise indefiniteness. According to Krifka (1995), Swahili uses the post-nominal numeral -moja 'one' to introduce an indefinite entity into the discourse context, and then more information about the entity follows. Considering the realisation of specificity, note that the objects in (17) above are ambiguous between specific and non-specific readings. It is not clear whether the speaker has a particular kitu 'thing' or shati 'shirt' in mind. The ambiguity between specificity and nonspecificity can be resolved by adding subsequent sentences, as in the following examples.

a. Lucy ameokota kitu. Nilikitupa jana.

[+spec]

'Lucy has picked up something. I threw it away yesterday.'

b. Paul amenunua shati. Utashangazwa na rangi yake. 'Paul has bought $a$ shirt. You will be surprised by its colour.'

a. Lucy ameokota kitu. Nitakwenda kujiridhisha ni nini. [-spec] 'Lucy has picked up something. I will go to find out what it is.'

b. Paul amenunua shati. Natamani kufahamu rangi yake. [-spec] 'Paul has bought a shirt. I would like to know its colour.'

In (18), the speaker has specific referents in mind. The specificity readings in these examples are clearly understood when considering the subsequent sentences. Thus the object NPs kitu 'something' and shati 'a shirt' are specific because the speaker can describe them if asked to do so. On the contrary, in (19) the speaker does not have particular referents in mind and cannot describe them if asked to do so. Likewise, the 
non-specificity readings in (19) are understood via considering the subsequent sentences. Such sentences provide the context for (non-)specificity distinctions in Swahili.

\section{Conclusion}

Swahili realises pragmatic definiteness at the interface between morphology, syntax and the context of interaction. Morphologically, Swahili uses subject markers, object markers, deictic demonstratives, anaphoric demonstratives, possessives, personal pronouns and proper nouns. Syntactically, it uses relative clause postmodifications for uniqueness and word order permutations (for definiteness in general). With respect to realising indefiniteness, first mention contexts have been noted to fulfil this function. As for specificity, Swahili simply relies on the context of interaction. Therefore, whereas definiteness is realised at the interface between morpho-syntactic and semantic-pragmatic domains, specificity is pragmatically inferred in Swahili. 
Kimambo: The morpho-syntactic and semantic-pragmatic realisation of definiteness and specificity in Swahili

\section{References}

Abbott, Barbara, 2006. Definiteness and indefiniteness. In Laurence R. Horn and Gregory Ward, eds., The Handbook of Pragmatics. Malden: Blackwell Publishing. Pp 122-149.

Allen, Keith, 1983. Anaphora, cataphora, and topic focusing, functions of the object prefix in Swahili. In Ivan Dihoff, ed., Current Approaches to African Linguistics 1. Dordrecht: Foris, Pp. 323-336.

Alnet, Aimee J., 2009. The clause structure of the Shimaore dialect of Comorian (Bantu). PhD dissertation. Graduate College of the University of Illinois.

Ashton, Ethel O., 1944. Swahili grammar (including intonation). Harlow: Longmans.

Barrett-Keach, Camillia, 1985. The syntax and interpretation of the relative clause construction in Swahili. New York: Garland.

Bresnan, Joan and Sam A. Mchombo, 1987. Topic, pronoun and agreement in Chichewa. Language 63:741-782.

Bresnan, Joan and Lioba Moshi, 1990. Object asymmetries in comparative Bantu syntax. Linguistic Inquiry 21.2: 147-185.

Cann, Ronnie, Kempson, Ruth. and Lutz Marten, 2005. The dynamics of language, an introduction. Amsterdam: Elsevier Academic Press.

Croft, William, 2003. Typology and universals. Cambridge: Cambridge University Press.

Dikilitas, Kenan and Meryem Altay, 2011. Acquisition sequence of four categories of non-generic use of the english definite article by Turkish speakers. NovitasROYAL (Research On Youth and Language) 5.2: 183-198.

Dryer, Matthew S., 2005. Definite articles. In Martin Haspelmath, Matthew S. Dryer, David Gil and Bernard Comrie, eds., The World Atlas of Language Structures (WALS). Oxford: Oxford University Press. Pp. 154-157.

Duarte, Fábio B., 2011. Tense encoding, agreement patterns, definiteness and relativization strategies in Changana. In Eyamba G. Bokamba, ed., Selected Proceedings of the 40th Annual Conference on African Linguistics. Somerville, MA: Cascadilla Proceedings Project Pp. 80-94.

Ekiert, Monika, 2007. The acquisition of grammatical marking of indefiniteness with the indefinite article a in L2 English. Teachers College, Columbia University Working Papers in TESOL \& Applied Linguistics. 7.1: 1-43.

Fishman, Anne S., 1978. The effect of anaphoric references and noun phrase organizers on paragraph comprehension. Journal of Literacy Research. 10.2: $159-170$.

Gambarage, Joash J., 2013. The pre-prefix in Nata, an interface account. In Olanike O. Orie and Karen W. Sanders, eds. Selected Proceedings of the 43rd Annual 
Conference on African Linguistics. Somerville: Cascadilla Proceedings Project. Pp. 163-176.

Givón, Talmy, 1978. Definiteness and referentiality. In Joseph. H. Greenberg, Charles. A. Ferguson, and Edith A. Moravcsik, eds., Universals of Human Language. Stanford: Stanford University Press. Pp. 291-330.

Guthrie, Malcolm, 1967. Comparative Bantu, an Introduction to the Comparative Linguistics and Prehistory of the Bantu Languages. Vols 1-4, London: Gregg Press.

Haddon, Ernest B., 1955. Swahili Lessons, Cambridge: W. Heffer and Sons.

Hinnebusch, Thomas J. and Robert S. Kirsner, 1980. On the inference of "Inalienable Possession" in Swahili. Journal of African Languages and Linguistics 2: 1-16.

Hualde, José I., 1989. "Double object constructions in KiRimi.” In Paul Newman and Robert Botne, eds., Current Approaches to African Linguistics. Dordrecht: Foris. Pp. 179-189.

Hyman, Larry M. and Francis Katamba, 1993. The augment in Luganda, syntax or pragmatics? In Sam A. Mchombo, ed., Theoretical Aspects of Bantu Grammar. Stanford: C.S.L.I. Pp. 209-256.

Iorio, David E., 2011. The noun phrase in Kibembe (D54). Newcastle Working Papers in Linguistics 17: 46-66.

Irmer, Matthias, 2011. Bridging Inferences, Constraining and Resolving Underspecification in Discourse Interpretation. Berlin: Mouton de Gruyter.

Keach, Camillia N., 1995. Subject and object markers as agreement and pronoun incorporation in Swahili. In Akinbiyi Akinlabi, ed., Theoretical Approaches to African Linguistics. Trenton, NJ: African World Press. Pp. 109-116.

Kimambo, Gerald E., 2018. Object marking in Swahili, definiteness, specificity or both? South African Journal of African Languages 38.1:27-35.

Krifka, Manfred, 1995. Swahili. In Joachim Jacobs, Arnim von Stechow, Wolfgang Sternefeld, and Theo Vennemann, eds., Syntax, an International Handbook of Contemporary Research. Berlin: Walter de Gruyter. Pp. 1397-1418.

Lipps, Jonathan, 2011. A Lexical-functional analysis of Swahili relative clauses. MPhil thesis. Oxford University.

Loogman, Alfons, 1965. Swahili Grammar and Syntax. Pittsburgh, PA: Duquesne University Press.

Lowrens, L.J., 1981. 'Relevance of the notions 'given' and 'new' discourse information in the study of Northern Sotho syntax." South African Journal of African Languages 1.1: 21-49.

Lyons, Christopher, 1999. Definiteness. Cambridge: Cambridge University Press.

Maho, Jouni F., 2009. The online version of the new updated Guthrie list, a referential classification of the Bantu languages [Online]. Retrieved: May 27, 2015. Available at: http://goto.glocalnet.net/mahopapers/nuglonline.pdf.

Marten, Lutz and Deograsia Ramadhani, 2001. An overview of object marking in 
Kimambo: The morpho-syntactic and semantic-pragmatic realisation of definiteness and specificity in Swahili

Kiluguru. SOAS Working Papers in Linguistics 11: 259-275.

Mojapelo, Mampaka L., 2013. Re-examining the relationship between the subject agreement morpheme and (in)definiteness in Northern Sotho. Literator 34.1: 18.

Mugari, Victor, 2013. Object marking restrictions on Shona causative and applicative constructions. Southern African Linguistics and Applied Language Studies 31.2:151-160.

Mwangi, Iribe. and P.C. Kihara, 2011. The Gĩkũyũ reference phrase: A role and reference grammar [RRG] perspective. Baraton Interdisciplinary Research Journal 1.2: 46-57.

Nurse, Derek and Gérard Philippson, 1977. Tones in Old Moshi (Chaga). Studies in African Linguistics 8.1: 49-80.

Perrot, D.V., 1951. Swahili. London: Hodder and Stoughton.

Perrot, D.V., 1969. Teach yourself Swahili. New York: David McKay Company, Inc.

Petzell, Malin, 2003. What is the funtion of the preprefix in Kagulu? In Maia och Susanna Karlsson Andreasson, ed., Language.doc. Goteborg: Goteborg University Open Archive. Pp. 1-13.

Polomé, Edgar C., 1967. Swahili Language Handbook. Washington, DC: Center for Applied Linguistics.

Progovac, Ljiliana, 1993. Non augmented NPs in Kinande as negative polarity. In Sam A. Mchombo, ed., Theoretical Aspect of Bantu Grammar I. California: CSLI Publication. Pp. 257-270.

Radden, Günter and René Dirven, 2007. Cognitive English Grammar. Philadelphia: John Benjamin Publishing.

Rezai, Mohammad J and Ali Jabbari, 2010. The acquisition of definiteness feature by Persian L2 learners of English. The Journal of Teaching Language Skills (JTLS) 2.2: $123-154$.

Riedel, Kristina, 2009. Object marking in wh-questions in Bantu. In Akinloye Ojo and Lioba Moshi, eds., Selected Proceedings of the 39th Annual Conference on African Linguistics. Somerville, MA: Cascadilla Proceedings Project. Pp. 67-76.

Seidl, Amanda and Alexis Dimitriadis, 1997. The discourse function of object marking in Swahili. Chicago Linguistic Society 33: 373-387.

Świątek, Artur, 2014. The Order of the Acquisition of the English Article System by Polish Learners in Different Proficiency Groups. New Castle: Cambridge Scholars Publishing.

Valenzuela, Elena and Bede McCormack, 2013. The syntax-discourse interface and the interface between Generative Theory and pedagogical approaches to SLA. In Melinda Whong, Kook-Hee Gil and Heather Marsden, eds., Universal Grammar and the Second Language Classroom. Dordrecht: Springer. Pp. 101-114. 
Van de Velde, Mark, 2005. The order of noun and demonstrative in Bantu. In Koen Bostoen and Jacky Maniacky, eds., Studies in African Comparative Linguistics with Special Focus on Bantu and Mande. Tervuren: Royal Museum of Central Africa. Pp. 425-441.

Visser, Marianna, 2008. Definiteness and specificity in the isiXhosa determiner phrase. South African Journal of African Languages 1: 11-29.

Vitale, Antony, 1981. Swahili Syntax. Dordrecht: Foris Publications Holland.

Woolford, Ellen, 1999. Animacy hierachy effects on object agreement. In Paul Kotey, ed., New Dimensions in African Linguistics and Languages (Trends in African linguistics 3). Pp. 203-216. Retrieved: May 12 2015. Available at: http://people.umass.edu/ellenw/.

Zamparelli, Roberto, 2005. Introduction, some questions about (in)definiteness. Lingua, 115: 759-766.

Zeller, Jochen, 2012. Object marking in isiZulu. Southern African Linguistics and Applied Language Studies 30.2: 219-235.

Zeller, Jochen, 2008. The subject marker in Bantu as an antifocus marker. Stellenbosch Papers in Linguistics 38: 221-254.

Zerbian, Sabine, 2007. Investigating prosodic focus in Northern Sotho. In Enoch Oladé Aboh, Katharina Hartmann, and Malte Zimmerman, eds., Focus Strategies in African Languages. Berlin: Mouton de Gruyter. Pp. 55-79. 